УДК 316.774:159.923

\title{
ХЕШТЕГИ КАК ОТРАЖЕНИЕ РЕПРЕЗЕНТАЦИЙ ОБРАЗОВ БУДУЩЕГО «ЦИФРОВЫМИ АБОРИГЕНАМИ»
}

\author{
Конюхова Татьяна Васильевна, \\ konykhova@tpu.ru \\ Родионова Елена Викторовна, \\ eva@tpu.ru
}

Национальный исследовательский Томский политехнический университет, Россия, 634050, Томск, пр. Ленина, 30

\begin{abstract}
Конюхова Татьяна Васильевна, кандидат философских наук, доцент отделения социально-гуманитарных наук Школы базовой инженерной подготовки Национального исследовательского Томского политехнического университета.
\end{abstract}

Родионова Елена Викторовна, кандидат философских наук, доцент отделения социально-гуманитарных наук Школы базовой инженерной подготовки Национального исследовательского Томского политехнического университета.

В статье освещается вопрос визуальной репрезентации образа будущего в повседневности пользователей социальных медиа на основании хештегов, входящих в ядерно-периферическую структуру представлений «цифровых аборигенов». Предполагалось, что эмоциональное благополучие выступает атрибутивной составляющей успешной карьеры в будущем для молодых пользователей сети Instagram и отражается в практиках визуализации через используемые ими хештеги. Целевой аудиторией исследования стали 170 молодых людей (118 женского пола и 52 мужского) в возрасте 18-25 лет, являющихся, по субъективной оценке, активными пользователями социальных медиа. Сбор массива данных осуществлялся в августе-сентябре 2020 г. В исследовании использовались метод свободных словесных ассоциаций и прототипический анализ по П. Вержесу. Соотношение образов будущего по анализируемым в статье социальным конструктам «Эмоциональное благополучие в будущем» и «Карьера в будущем» по подгруппам «для себя» и «для России» среди респондентов позволяет отметить, что общая тональность хештегов, предложенных участниками исследования, является преимущественно позитивной. Общими хештегами, так или иначе перекликающимися в ядре и зонах потенциальных изменений, для двух конструктов являются \#счастье, \#благополучие, \#успех, \#уверенность, \#свобода, \#спокойствие. Сравнительный анализ полученного массива хештегов позволяет говорить о том, что в практиках визуализации в сети Instagram через публикуемые хештеги молодежи имеет место определенная взаимосвязь эмоционального благополучия (как атрибутивной составляющей карьерного развития) и собственно успешной карьеры в будущем. Это формирует основу для развития новых профессиональных умений через уверенность в себе, положительные ошущения, степень общественной активности.

Ключевые слова: Хештег, образ будущего, цифровые аборигены, эмоциональное благополучие, карьера.

\section{Введение}

Образы возможного будущего, сопряженные с внутренним миром личности и представлениями о перспективах развития своей страны, изучаются на стыке социологии, психологии и философии, потому что отражают жизненные позиции и устремления граждан. Уже сейчас, анализируя контент виртуальной реальности социальных сетей и 
имеющиеся маркеры, можно проследить перспективы психологических установок и ожиданий, роль эмоциональной компоненты и готовности нынешних молодых людей прикладывать усилия для достижения результата.

Выстраивание образа будущего и самоосознание себя в нем - «исключительное достояние человека, который при этом воспринимает себя как субъект сознания, общения и действия, становясь в непосредственное отношение к самому себе» [1, с. 32]. Более того, будущее - это всегда люди, которые не только формируют представления о перспективах развития, но и будут реализовывать все задуманное. В первую очередь здесь следует говорить о молодежи, которую сегодня называют «цифровым поколением», «цифровыми аборигенами», «сетевым поколением» [2-6].

Миллениалы появились после цифровой революции в 1980-х г., когда широко стали применяться персональные портативные коммуникационные технологии и начала нарастать вовлеченность человека в цифровую реальность. Сегодня «цифровыми аборигенами» уже рождаются, потому что с первых дней жизни дети растут в среде, богатой различными технологиями. Виртуальное пространство, Интернет вносят значительный вклад в формирование их мировосприятия, картины мира. Считается, что «цифровое поколение» обладаете более высокими когнитивными способностями, нейропластичностью, податливостью психики, что позволяет им обрабатывать информацию принципиально разными способами, отличающимися скоростью и интерактивностью [7]. Концепция поколения «цифровых аборигенов» основана на том, что раннее знакомство и частое использование информационно-коммуникативных технологий меняют восприятия действительности $[2,3]$, в том числе наполняют ее идеей «fun как повседневного удовольствия и счастья» $[8$, с. 192] и возможностью получать поддержку от людей, в том числе эмоциональную, не только при личном контакте, но и т. н. «цифровую поддержку» с помощью цифровых средств [9]. Это отражается на формировании образов желаемой реальности.

Иными словами, мобильно-сетевое мышление, складывающееся в цифровой реальности, влияет на определение социальной идентичности личностей цифровых аборигенов и восприятие себя и образа своего будущего. Примеряя различные социальные роли, молодые люди создают визуальные образы и представления о том, какой будет страна, как выстраивать свою карьеру, что для этого нужно, как обрести благополучие в жизни и т. д.

Образ будущего страны непосредственно связан с формированием личной идентичности и невозможен без субъекта, его создающего. Сегодня онлайн-пространство в равной степени с оффлайн-средой влияют на его становление. Особую роль, на наш взгляд, играет виртуальный мир социальных медиа, включенных в «децентрированное плюралистичное цифровое пространство» [10, с. 40]. Данные медиа формируют через цифровую реальность социально-ценностные и смысловые установки граждан о будущем России, предпочтения и ожидания, получающие социальное одобрение и поддержку. Свое выражение эти установки, ожидания и предпочтения находят в хештегах, которые выступают маркерами или метками, кратко описывающими тематику сообщения (поста) и визуализирующими образы пользователей.

Согласно статистике в России социальными сетями с наибольшей вовлеченностью пользователей являются YouTube, ВКонтакте и Instagram [11]. Последний замыкает тройку лидеров и является одной из самых популярных социальных сетей России, где хештеги выступают неотъемлемой частью практически любой публикации. Именно поэтому исследование образа будущего Я и России по хештегам проводилось на ее платформе. 


\section{Методы исследования}

В рамках нашего исследования проводился анализ визуальной репрезентации образа будущего Я и России на основании хештегов по пяти социальным конструктам (Карьера в будущем, Уверенность в будущем, Политическое благополучие в будущем, Технологичное благополучие в будущем, Эмоциональное благополучие в будущем), включающим разделение внутри каждого конструкта на две подгруппы («Образ будущего для себя», «Образ будущего для других»).

В работе приводится часть результатов, направленная на выявление наличия или отсутствия взаимосвязи эмоционального благополучия и карьеры в представлениях молодежи. Выбор данных конструктов для описания обусловлен существованием стереотипа о том, что в сознании цифрового поколения (в данном случае 18-25 лет) доминирует стремление к достижению (успеха, благополучия и пр.), но при этом отмечается, что упорным трудом этого она не хочет добиваться. Иными словами, в сознании изучаемой целевой аудитории имеют место представления, что успешность личности сегодня во многом раскрывается через уверенность в себе, положительные ощущения, степень общественной активности (включение в различные многоуровневые и многоаспектные связи и отношения с другими людьми, приобретение умений взаимодействовать с ними) [12] и в меньшей степени через упорство, трудолюбие, постепенный профессиональный и карьерный рост и наличие документа, подтверждающего квалификацию.

Объектом исследования является визуальная репрезентация образа будущего Я и России в повседневности пользователей социальных медиа.

Предметом - практики визуализации социальных конструктов «Карьера в будущем», «Эмоциональное благополучие в будущем» в сети Instagram через хештеги пользователей в возрасте 18-25 лет.

Цель: анализ визуальной репрезентации образа будущего Я и России на основании хештегов, входящих в ядерно-периферическую структуру представлений субъектов выделенных социальных конструктов, применяемых пользователями социальных медиа.

Гипотеза исследования: мы предполагаем наличие в представлениях молодежи взаимосвязи между эмоциональным благополучием и карьерой, т. е. рассмотрение эмоционального благополучия как атрибутивной составляющей карьеры в будущем, что находит отражение в практиках визуализации в сети Instagram через публикуемые ими хештеги.

Методологию исследования составили:

1. Метод свободных словесных ассоциаций. Для получения информации о наполнении выделенных в рамках исследования социальных конструктов нами выбрана проективная методика - свободных словесных ассоциаций. Данная методика активно используется в современных исследованиях для определения субъектом различных составляющих внешнего и внутреннего мира $[13,14]$. Методика позволяет получить объективные результаты через выявленные ассоциации, сложившиеся у индивида в его предшествующем опыте, и легко поддается стандартизации.

2. Прототипический анализ по П. Вержесу [15]. Применялся для выявления структур указанных конструктов и анализа их содержания. Согласно данной методике, можно выделить ядро (устойчивую часть) и периферию (часть, подверженную изменениям). Анализ структуры проводится по двум параметрам: частота появления ассоциации в ответах респондентов и ранг ассоциации [16]. Как отмечают И.Б. Бовина, Л.Ю. Драгульская и элементы ядра представления придают смысл всему представлению, они имеют наибольшее количество связей с остальными элементами представления. Периферическая система представления играет второстепенную 
роль с точки зрения структуры представления. Это наиболее подвижная и пластичная часть, она наиболее живая и конкретная и за ее счет осуществляется связь ядра представления с реальностью, задается контекст представления [17].

Обоснование выборки: для достижения цели и решения поставленных задач было проведено экспериментальное эмпирическое исследование среди пользователей сети Instgram. Способ отбора респондентов не требует расчленения генеральной совокупности и осуществляется методом простой случайной (вероятностной) бесповторной выборки.

Фактически основной массив выборки составляли студенты Томского политехнического университета (ТПУ). Опрос проходил в августе-сентябре 2020 г. с помощью опросника «Конструирование образа будущего в социальных медиа», созданного на платформе Google Drive в сети Интернет [18]. На момент окончания сбора полевой информации опросник заполнили 170 человек.

\section{Результаты и дискуссионные вопросы}

В опросе на первом этапе приняли участие 170 респондентов в возрасте 18-25 лет, из которых 118 (69,4 \%) составили женщин и 52 (30,6 \%) мужчины. Больше половины участников опроса, а именно 54,1 \% (92 чел.) относят себя, по субъективным оценкам, к активным пользователям социальных медиа, а именно сети Instagram. Это дает нам основание считать, что полученные в результате исследования хештеги, отражающие представления, установки, социально ценностные и смысловые конструкты в достаточно мере достоверны.

Опросник составлялся с учетом необходимости разделить заявленные социальные конструкты на две подгруппы. Исходя из этого, мы анализировали каждый конструкт по двум направлениям «Представление о будущем для себя» и «Представление о будущем для других (для страны)».

Опрос «Образы будущего России» методом свободных словесных ассоциаций. Конструкт «Эмоциональное благополучие в будущем» включил в целом повторяемые с разной частотностью 643 хештега. По подгруппе личного эмоционального благополучия лидером оказался «прямой» хештег \#эмоции с частотностью упоминания 21, далее в тройке «лидеров» следовали хештеги \#счастье - 18 маркеров, \#благополучие - 10 . Наименее упоминаемыми хештегами были \#дети, \#МентальноеЗдоровье, \#Мояжизнь, \#переезд, \#Позитив, \#счастьевсемье, \#удовлетворение, \#эмоциональнаястабильность. По подгруппе эмоционального благополучия для страны доминирующим хештегом оказался \#россия (13 упоминаний). Важно, что он в значительной степени отставал от лидирующего в первой подгруппе хештега \#эмоции (21 упоминание). Повторяющийся в обеих группах хештег \#благополучие расположился во второй подгруппе на второй строчке с частотностью 11, а в первой - на четвертой строке с частотностью 8. Наименее популярными среди повторяющихся маркеров в отношении образа эмоционального благополучия для России выступили хештеги \#дружба, \#МентальноеЗдоровье, \#перемены, \#радость, \#развитие, \#Россиянедлягрустных, \#эмоциональноеблагополучиероссиян.

Конструкт «Карьера в будущем» - 624 ассоциации (с учетом повторяющихся с разной частотностью хештегов). И оказался весьма интересным с точки зрения анализа, т. к. он отразил как проблемные аспекты, вызванные ростом безработицы и неопределенности карьерных перспектив в условиях повышенной тревожности из-за пандемии коронавируса в 2020 г., так и показал, чему уделяют больше внимания граждане страны, размышляя о своем будущем и будущем других в части наличия/отсутствия работы. «Прямой» хештег \#карьера уверенно занимает первую строку в обеих подгруппах по 
анализируемому конструкту с частотностью упоминания 25 в подгруппе «для себя» и 23 в подгруппе «для других (для страны)». Ситуация с хештегом \#успех характеризуется удивительной полярностью, т. к. рассуждения респондентов относительно собственного карьерного успеха являются позитивными и это отражается в том, что данный маркер по частотности упоминания занимает третью позицию (8 упоминаний респондентами) наряду с хештегом \#моебудущее. Иными словами, опрошенные неразрывно связывают свое будущее с успешной карьерой.

Рассуждения о своей карьере и будущем также сопровождаются упоминанием позитивно окрашенных хештегов \#развитие, \#бизнес, \#интерес, \#мечты, \#счастье. Хотя частота их упоминаний относительно низка, тем не менее это свидетельствует об имеющейся тенденции к положительной оценке карьерных перспектив в будущем.

В ситуации же размышления о карьере других в будущем в масштабах страны хештег \#успех размещается в группе наименее упоминаемых, наряду с хештегом \#удаленка. Это свидетельствует о том, что успех при удаленной работе, без общения в коллективе маловероятен, по мнению респондентов, и не отражает возможных перспектив, связанных с карьерным ростом и уверенностью в будущем, в том числе и финансовой стабильностью.

Обработка данных с помощьью прототипического анализа по П. Вержесу. Полученные данные обрабатывались с помощью пакета статистических программ SPSS. Прежде всего производилось ранжирование указанных респондентами ассоциаций в порядке частоты их употребления. Ассоциации, указанные менее $5 \%$ респондентов, т. е. носящие случайный характер и обусловленные индивидуальными особенностями респондентов, дальнейшей обработке не подвергались. Из анкет в расчет были взяты те, где указаны не менее 4 ассоциаций по каждой из указанных групп. В результате у нас осталось 58 респондентов.

По подгруппе личного эмоционального благополучия социального конструкта «Эмоциональное благополучие в будущем»: всего респондентами было указано 331 acсоциация, в среднем составило 5,7 понятий на человека, частота ассоциации - 10,67, средний ранг $-3,43$.

В результате анализа содержания социальных представлений была выделена структурная композиция социальных представлений (табл. 1).

По подгруппе «эмоциональное благополучие россиян в будущем» всего респондентами было указано 312 ассоциаций, в среднем составило 6,05 понятий на человека, частота ассоциации - 10,4, средний ранг $-2,85$. В результате анализа содержания социальных представлений была выделена структурная композиция социальных представлений (табл. 2).

В целом по конструкту «Эмоциональной благополучие» зона периферии составила 31 , ядро - 9 хештегов (4 и 5 для каждой подгруппы). Одинаковые для двух групп («для себя», «Для России») \#эмоции, \#будущее, \#благополучие. По семантическому наполнению «для себя» отметим важный, на наш взгляд, хештег - \#счастье.

По подгруппе «моя карьера в будущем» социального конструкта «Карьера и будущее» всего респондентами было указано 342 ассоциации, в среднем составило 5,9 понятий на человека, частота ассоциации - 11,79 , средний ранг $-3,45$. В результате анализа содержания социальных представлений была выделена следующая структурная композиция социальных представлений (табл. 3).

Таблица 1. Структурная композиция социальных представлений о конструкте «Мое эмоциональное благополучие в будущем», которые формируются через 


\section{хештеги в социальной сети Instagram}

Table 1. Structural composition of social ideas about construct «My emotional well-being in the future», which are formed through hashtags on the Instagram social network

\begin{tabular}{|c|c|c|}
\hline $\begin{array}{l}\text { Критерии оценки } \\
\text { Evaluation criteria } \\
\end{array}$ & $\begin{array}{l}\text { Низкий ранг (менее 3,43) } \\
\text { Low rank (less than 3.43) }\end{array}$ & $\begin{array}{l}\text { Высокий ранг (более или равен } 3,43 \text { ) } \\
\text { High rank (greater than or equal to 3.43) }\end{array}$ \\
\hline $\begin{array}{l}\text { Высокая частота } \\
\text { встречаемости поня- } \\
\text { тия (более или равна } \\
10,67) \\
\text { High frequency of oc- } \\
\text { currence of the con- } \\
\text { cept (greater than or } \\
\text { equal to 10,67) }\end{array}$ & $\begin{array}{l}\text { Зона ядра (1)/Core zone (1): } \\
\text { эмоции/emotions; } \\
\text { счастье/happiness; } \\
\text { благополучие/well-being; } \\
\text { будущеe/future }\end{array}$ & $\begin{array}{l}\text { Зона потенциальных изменений (3) } \\
\text { Potential changes zone (3): } \\
\text { эмоциональноеблагополучие } \\
\text { emotionalwellbeing; } \\
\text { любовь/love; } \\
\text { спокойствиe/calm/peacefulness; } \\
\text { мир/peace; } \\
\text { МоеБудущеe/MyFuture; } \\
\text { психология/phycology; } \\
\text { семья/family; } \\
\text { уверенность/confidence }\end{array}$ \\
\hline $\begin{array}{l}\text { Низкая частота } \\
\text { встречаемости поня- } \\
\text { тия (менеe 10,67) } \\
\text { Low frequency of oc- } \\
\text { currence of the con- } \\
\text { cept (less than } 10,67 \text { ) }\end{array}$ & $\begin{array}{l}\text { Зона потенциальных изменений (2) } \\
\text { Potential changes zone (2): } \\
\text { моиэмоции/myemotions; } \\
\text { свобода/freedom; } \\
\text { стабильность/stability; } \\
\text { улыбка/smile; } \\
\text { успех/success }\end{array}$ & $\begin{array}{l}\text { Зона периферии/Periphery zone: } \\
\text { благополучиебудущего } \\
\text { wellbeingofthefuture; } \\
\text { дети/children; } \\
\text { ментальное3доровье/MentalHealth; } \\
\text { моеэмоциональноеблагополучие } \\
\text { myеmotionalwellbeing; } \\
\text { Мояжизнь/Mylife; } \\
\text { переезд/removal; } \\
\text { поддержка/support; } \\
\text { Позитив/Positive; } \\
\text { путьксебе/waytoyourself; } \\
\text { работа/job; } \\
\text { светлоебудущеe/brightfuture; } \\
\text { счастьевсемье/happinesstogether; } \\
\text { удовлетворение/pleasure; } \\
\text { эмоциональнаястабильность } \\
\text { етотіоnalstability; } \\
\text { я/mе }\end{array}$ \\
\hline
\end{tabular}

Таблица 2. Структурная композиция социальных представлений о конструкте «Эмоциональное благополучие россиян в будущем», которые формируются через хештеги в социальной сети Instagram

Table 2. Structural composition of social ideas about construct «Emotional well-being of Russians in the future», which are formed through hashtags on the social network Instagram

\begin{tabular}{|c|c|c|}
\hline $\begin{array}{l}\text { Критерии оценки } \\
\text { Evaluation criteria }\end{array}$ & $\begin{array}{l}\text { Низкий ранг (менее 2,85) } \\
\text { Low rank (less than 2,85) }\end{array}$ & $\begin{array}{l}\text { Высокий ранг (более или равен 2,85) } \\
\text { High rank (greater than or equal to } 2,85 \text { ) }\end{array}$ \\
\hline $\begin{array}{l}\text { Высокая частота } \\
\text { встречаемости по- } \\
\text { нятия (более или } \\
\text { равна } 10,4) \\
\text { High frequency of } \\
\text { occurrence of the } \\
\text { concept (greater than } \\
\text { or equal to 10,4) }\end{array}$ & $\begin{array}{l}\text { Зона ядра (1)/Core zone (1): } \\
\text { россия/russia; } \\
\text { благополучие/well-being; } \\
\text { эмоции/emotions; } \\
\text { будущеe/future; } \\
\text { благополучиероссиян/ wellbe- } \\
\text { ingofrussians }\end{array}$ & $\begin{array}{l}\text { Зона потенциальных изменений (3) } \\
\text { Potential changes zone (3): } \\
\text { будущеероссиян/futureofrussians; } \\
\text { эмоциональноеблагополучие/ } \\
\text { emotionalwellbeing; } \\
\text { мир/peace }\end{array}$ \\
\hline $\begin{array}{l}\text { Низкая частота } \\
\text { встречаемости по- } \\
\text { нятия (менее } 10,4)\end{array}$ & $\begin{array}{l}\text { Зона потенциальных изменений (2) } \\
\text { Potential changes zone (2): } \\
\text { будущеероссии/russianfuture; }\end{array}$ & $\begin{array}{l}\text { Зона периферии/Periphery zone: } \\
\text { дружба/friendship; } \\
\text { МентальноеЗдоровье/MentalHealth; }\end{array}$ \\
\hline
\end{tabular}




\begin{tabular}{|c|c|c|}
\hline $\begin{array}{l}\text { Low frequency of oc- } \\
\text { currence of the con- } \\
\text { cept (less than } 10,4 \text { ) }\end{array}$ & $\begin{array}{l}\text { россиядлягруст- } \\
\text { ных/russiaforsadpeople; } \\
\text { россияне/russians; } \\
\text { спокойствие/ calm/peacefulness; } \\
\text { справедливость/justice; } \\
\text { эмоциироссиян/ emotionsofrussians; } \\
\text { эмоциироссиянвбудущем/ } \\
\text { emotionsofrussiansinthefuture }\end{array}$ & $\begin{array}{l}\text { перемены/changes; } \\
\text { равенство/equality; } \\
\text { радость/joy; } \\
\text { развитие/development; } \\
\text { россиянедлягрустных russiafnotorsadpeople; } \\
\text { свобода/freedom; } \\
\text { свободаслова/freedomofspeech; } \\
\text { счастье/happiness; } \\
\text { творчество/creativity; } \\
\text { честность/honesty; } \\
\text { эмоциональнаястабильность } \\
\text { етотіоnalstability; } \\
\text { эмоциональноеблагополучиероссиян } \\
\text { етотіоnalwellbeingofrussians; } \\
\text { эмоциональноеизменение emotionalchange }\end{array}$ \\
\hline
\end{tabular}

Таблица 3. Структурная композиция социальных представлений о конструкте «Моя карьера в будущем», которые формируются через хештеги в социальной сети Instagram

Table 3. Structural composition of social ideas about construct «My career in the future», which are formed through hashtags on the social network Instagram

\begin{tabular}{|c|c|c|}
\hline $\begin{array}{l}\text { Критерии оценки } \\
\text { Evaluation criteria }\end{array}$ & $\begin{array}{l}\text { Низкий ранг (менее } 3,45) \\
\text { Low rank (less than 3,45) }\end{array}$ & $\begin{array}{l}\text { Высокий ранг (более или равен } 3,45 \text { ) } \\
\text { High rank (greater than or equal to } 3,45 \text { ) }\end{array}$ \\
\hline $\begin{array}{l}\text { Высокая частота } \\
\text { встречаемости по- } \\
\text { нятия (более или } \\
\text { равна } 11,79) \\
\text { High frequency of } \\
\text { occurrence of the } \\
\text { concept (greater than } \\
\text { or equal to } 11,79 \text { ) }\end{array}$ & $\begin{array}{l}\text { Зона ядра (1)/Core zone (1): } \\
\text { карьера/career; } \\
\text { моякарьера/mycareer; } \\
\text { моебудущеe/myfuture; } \\
\text { успех/success; } \\
\text { уверенность/confidence }\end{array}$ & $\begin{array}{l}\text { Зона потенциальных изменений (3) } \\
\text { Potential changes zone (3): } \\
\text { будущеe/future; } \\
\text { карьерныйрост/careergrowth; } \\
\text { БудущаяКарьера/FutureCareer; } \\
\text { работа/job; } \\
\text { благополучиe/wellbeing; } \\
\text { счастье/happiness }\end{array}$ \\
\hline $\begin{array}{l}\text { Низкая частота } \\
\text { встречаемости по- } \\
\text { нятия (менее } 11,79 \text { ) } \\
\text { Low frequency of oc- } \\
\text { currence of the con- } \\
\text { cept (less than } 11,79 \text { ) }\end{array}$ & $\begin{array}{l}\text { Зона потенциальных изменений (2) } \\
\text { Рotential changes zone (2): } \\
\text { IT/IT; } \\
\text { дети/children; } \\
\text { дизайн/design; } \\
\text { Моякарьеравбудущем } \\
\text { Мусаreerinthefuture; } \\
\text { спокойствие/calm/peacefulness; } \\
\text { развитие/development; } \\
\text { я/mе; } \\
\text { Яучитель/Iamateacher; } \\
\text { свобода/freedom }\end{array}$ & $\begin{array}{l}\text { Зона периферии/Periphery zone: } \\
\text { бизнес/business; } \\
\text { востребованнаяпрофессия } \\
\text { demandedprofession; } \\
\text { интерес/interest; } \\
\text { карьерабудущего/careerofthefuture; } \\
\text { Карьерныевозможностибудущего } \\
\text { Саreeropportunitiesofthefuture; } \\
\text { любимаяработа/favoritework; } \\
\text { любовь/love; } \\
\text { мечты/dreams; } \\
\text { моябудущаякарьера/myfuturecareer; } \\
\text { ПолитехКручеВсех } \\
\text { Роlуtесhisthecoolest; } \\
\text { творчество/creativity }\end{array}$ \\
\hline
\end{tabular}

По подгруппе «карьера россиян в будущем». Всего респондентами было указано 282 ассоциации, в среднем составило 4,86 понятий на человека, частота ассоциации 10,85 , средний ранг - 3,14. В результате анализа содержания социальных представлений была выделена структурная композиция социальных представлений (табл. 4).

Таблица 4. Структурная композиция социальных представлений о конструкте «Карьера россиян в будущем», которые формируются через хештеги в социальной сети Instagram 
Table 4. Structural composition of social ideas about construct «Career of Russians in the future», which are formed through hashtags on the social network Instagram

\begin{tabular}{|c|c|c|}
\hline $\begin{array}{l}\text { Критерии оценки } \\
\text { Evaluation criteria }\end{array}$ & $\begin{array}{l}\text { Низкий ранг (менее 3,14) } \\
\text { Low rank (less than } 3,14 \text { ) }\end{array}$ & $\begin{array}{c}\text { Высокий ранг (более или равен } 3,14) \\
\text { High rank (greater than or equal to } \\
3,14)\end{array}$ \\
\hline $\begin{array}{l}\text { Высокая частота встре- } \\
\text { чаемости понятия } \\
\text { (более или равна 10,85) } \\
\text { High frequency of occur- } \\
\text { rence of the concept } \\
\text { (greater than or equal to } \\
10,85 \text { ) }\end{array}$ & $\begin{array}{l}\text { Зона ядра (1)/Core zone (1): } \\
\text { карьера/career; } \\
\text { Россия/Russia; } \\
\text { Карьерароссиян/Careerofussians }\end{array}$ & $\begin{array}{l}\text { Зона потенциальных изменений (3) } \\
\text { Potential changes zone (3): } \\
\text { будущеe/future; } \\
\text { россияне/russians; } \\
\text { Карьерароссиянвбудущем } \\
\text { Careerofruaainsinthefuture }\end{array}$ \\
\hline $\begin{array}{l}\text { Низкая частота встреча- } \\
\text { емости понятия (менее } \\
10,85 \text { ) } \\
\text { Low frequency of occur- } \\
\text { rence of the concept (less } \\
\text { than } 10,85 \text { ) }\end{array}$ & $\begin{array}{l}\text { Зона потенциальных изменений (2) } \\
\text { Potential changes zone (2): } \\
\text { карьерабуду- } \\
\text { щего/careerofthefuture; } \\
\text { карьерныйрост/careergrowth; } \\
\text { работа/job; } \\
\text { развитие/development }\end{array}$ & $\begin{array}{l}\text { Зона периферии/Periphery zone: } \\
\text { Россия/Russia; } \\
\text { Бизнес/Business; } \\
\text { БудущаяКарьера/FutureCareer; } \\
\text { будущеероссиян/futureofrussians; } \\
\text { будущеестраны/futureofthecountry; } \\
\text { возможности/opportunities; } \\
\text { деньги/mоnеу; } \\
\text { карьера_pоссиян/career_russians; } \\
\text { карьеравроссии/careerinrussia; } \\
\text { Карьерныевозможности } \\
\text { сагеегорроrtunities; } \\
\text { ПеременТребуютHaшиCepдца } \\
\text { ОurНеаrtsDетаndChanges; } \\
\text { уверенность/сопfidence; } \\
\text { удаленка/remоte; } \\
\text { успех/suссеss; } \\
\text { успешнаякарьера/sucsessfulcareer }\end{array}$ \\
\hline
\end{tabular}

В целом по конструкту «Карьера и будущее» объем зоны периферии составил 27 хештегов, ядро - 7 (4 и 3 для каждой подгруппы). Одинаковый для двух групп («для себя», «Для России») только один «прямой» - \#карьера. По семантическому наполнению «для себя» отметим важный, на наш взгляд, хештег \#успех.

Как видно из проведенного анализа, ядро по социальным конструктам «Эмоциональное благополучие в будущем» и «Карьера и будущее» ни в одной из подгрупп (для себя, для России) не имеет одинаковых хештегов, что, с одной стороны, не позволяет говорить нам о прямой связи эмоционального благополучия и успешной карьере в представлениях молодежи. С другой стороны, стоит обратить внимание на сравнение ядра и зон потенциальных изменений в подгруппе «для себя». Согласно методологии П. Вержеса, вторая зона потенциальных изменений - это ассоциации, которые наиболее сильно подвержены изменениям и возможен в ближайшем времени их переход либо в зону ядра представления, либо в собственно периферическую зону, либо выход данных понятий из структурных компонентов социального представления. Это ассоциации с невысокой частотностью, но первых рангов, т. е. указываются меньшинством, но в первую очередь; третья зона потенциальных изменений - это ассоциации с высокой частотой встречаемости, но в последних рангах (часто связывают с влиянием СМИ).

Соответственно, мы можем отметить шесть общих хештегов для двух конструктов (\#счастье, \#благополучие, \#успех, \#уверенность, \#свобода, \#спокойствие), так или иначе перекликающихся в ядре и зонах потенциальных изменений. Например, в ядре «Эмоциональное благополучие» мы видим \#счастье, \#благополучие, которые в социальном 
конструкте «Карьера и будущее» находятся во второй зоне. В ядре «Карьера и будущее» - \#успех, \#уверенность, которые во втором конструкте находятся соответственно в третьей и второй зоне. Более полное сравнение шести хештегов представлено в табл. 5.

Таблища 5. Сравнение шести хештегов по двум социальным конструктам «Эмоциональное благополучие в будущем» и «Карьера и будущее»

$$
\text { (в подгруппе «для себя») }
$$

Table 5. Comparison of six hashtags for two social constructs «Emotional well-being in the future» and «Career and the future» (in the subgroup «for myself»)

\begin{tabular}{|c|c|c|c|}
\hline $\begin{array}{c}\text { Социальный } \\
\text { конструкт } \\
\text { Social construct }\end{array}$ & Ядро/Core & $\begin{array}{c}\text { Вторая зона потенциаль- } \\
\text { ных изменений } \\
2^{\text {nd }} \text { potential changes zone }\end{array}$ & $\begin{array}{c}\text { Третья зона потенци- } \\
\text { альных изменений } \\
3^{\text {rd }} \text { potential changes zone }\end{array}$ \\
\hline $\begin{array}{l}\text { «Эмоциональное } \\
\text { благополучие в бу- } \\
\text { дущем» } \\
\text { «Emotional well-be- } \\
\text { ing in the future» }\end{array}$ & $\begin{array}{l}\text { \#счастье/\#happiness; } \\
\text { \#благополучие/\#wellbeing }\end{array}$ & $\begin{array}{l}\text { \#спокойствие/ } \\
\text { \#calm/peacefulness; } \\
\text { \#уверенность/\#confidence }\end{array}$ & $\begin{array}{l}\text { \#успех/\#success; } \\
\text { \#свобода/\#freedom }\end{array}$ \\
\hline $\begin{array}{l}\text { «Карьера и будущее» } \\
\text { «Career and future» }\end{array}$ & $\begin{array}{l}\text { \#успех/\#success; } \\
\text { \#уверенность/\#confidence }\end{array}$ & $\begin{array}{l}\text { \#счастье/\#happiness; } \\
\text { \#благополучие/ } \\
\text { \#wellbeing }\end{array}$ & $\begin{array}{l}\text { \#спокойствие/ } \\
\text { \#calm/peacefulness; } \\
\text { \#свобода/\#freedom }\end{array}$ \\
\hline
\end{tabular}

Сравнительный анализ двух социальных конструктов позволяет говорить о подтверждении отдельных следствий нашей гипотезы, а именно, что в практиках визуализации в сети Instagram через публикуемые хештеги молодежи наблюдается взаимосвязь эмоционального благополучия и успешной карьеры в будущем, однако это не проявляется как явная, четко сформулированная установка. Она скорее находится на стадии формирования, и на ее становление влияют другие пользователи сети. Соответственно, у «цифровых аборигенов» имеет место представление об эмоциональном благополучии как о некой атрибутивной составляющей карьерного развития, что, в свою очередь, создает прочную базу для развития новых профессиональных умений через уверенность в себе, положительные ощущения, степень общественной активности.

\section{Заключение}

Таким образом, можно отметить, что процесс «хештегирования» представляется как дискурсивный, исследование этого синтаксического явления позволяет раскрыть структурную взаимосвязь человека и языка [19, с. 108]. Хештеги являют собой определенную систему взаимосвязанных речевых действий акторов, как произвольных, так и регулируемых, результатом которых становится достижение коммуникативной цели [20].

Соответственно, создание/использование хештега происходит на основе субъективного отражения реальности, а также под воздействием принципа работы хештега как инструмента привлечения аудитории.

Говоря о соотношении образов будущего по выделенным социальным конструктам «Эмоциональное благополучие», «Карьера и будущее». для себя и для России среди целевой группы пользователей социальной сетью Instagram, можно отметить, что общая тональность хештегов, предложенных респондентами при формировании перечня методом свободных ассоциация, является преимущественно позитивной. Это свидетельствует о том, что молодежь в целом смотрит в будущее с хорошим настроем и хочет видеть перспективы дальнейшего развития. Отдельные отрицательно заряженные по тональности хештеги показывают, что проблемные аспекты есть и их нельзя упускать из 
виду. В отношении оценки будущего для себя респонденты более позитивны, они понимают, что сами являются «творцами своего счастья» и готовы прикладывать усилия для достижения результатов.

Также в процессе анализа выявлена формирующаяся тенденция в представлениях изучаемой целевой группы - рассмотрение эмоционального благополучия как атрибутивной составляющей карьеры в будущем. И как отмечает Г.В. Черняева, при повышении эмоционального благополучия происходит «не только изменение внутреннего контекста (рост удовлетворенности собой, позитивной самооценки, оптимизма и уверенности в будущих успехах), но и изменение внешнего контекста личности (одобрение и признание окружающих, позитивные внешние оценки, формирование новых социальных взаимодействий и отношений, позитивная динамика социально-психологических ролей и статусов), которое может находить отражение даже в устойчивых, медленно изменяющихся компонентах общественного мнения» [21, с. 341-342].

Исследование выполнено при финансовой поддержке РФФИ и ЭИСИ в рамках научного проекта № 20-011-31100.

\section{СПИСОК ЛИТЕРАТУРЫ}

1. Петрова В.Н. Методика изучения образа возможного будущего // Сибирский психологический журнал. - 2002. - № 16-17. - С. 32-36.

2. Prenksy M. Digital natives, digital immigrants // On the Horizon. - 2001. - V. 9 (5). - P. 1-6.

3. Prenksy M. Digital natives, digital immigrants. P. II. Do they really think differently? // On the Horizon. 2001. - V. 9 (6). - P. 1-6.

4. Thompson P. The digital natives as learners: technology use patterns and approaches to learning // Computers \& Education. - 2013. - V. 65. - P. 12-33. DOI: https://doi.org/10.1016/j.compedu.2012.12.022.

5. Bowe B.J., Wohn D.Y. Are there generational differences? Social media use and perceived shared reality // Proc. of the 2015 International Conference on Social Media \& Society (SMSociety '15). - Toronto, Ontario, Canada, 2015. - P. 1-5. DOI: https://doi.org/10.1145/2789187.2789200.

6. Barak M. Are digital natives open to change? Examining flexible thinking and resistance to change // Computers \& Education. - 2018. - V. 121. - P. 115-123. DOI: https://doi.org/10.1016/j.compedu.2018.01.016.

7. Teo T. Do digital natives differ by computer self-efficacy and experience? An empirical study // Interactive Learning Environments. - 2016. - V. 24 (7). - P. 1725-1739. DOI: 10.1080/10494820.2015.1041408.

8. Арпентьева М.Р. Цифровые кочевники осваивают мир // Дружба Народов. - 2018. - № 8. - С. 192-196.

9. Any time and place? Digital emotional support for digital natives / T. Colasante, L. Lin, K. de France, T. Hollenstein // American Psychologist. Advance online publication. - 2020. - DOI: https://doi.org/10.1037/amp0000708.

10. Соловьева Л.М. Цифровая идентичность как новый вид идентичности человека информационной эпохи // Общество: философия, история, культура. - 2018. - № 12. - С. 40-43.

11. Статистика социальных сетей в России 2020. URL: https://livedune.ru/blog/statistika_socsetej_v_rossii// (дата обращения 12.10.2020).

12. Тугушева А.Р. Представления о социальной успешности и личностное самоопределение юношества: автореф. дис. ... канд. психол. наук. - Самара, 2007. -24 с.

13. Ильина В.А. Ассоциативный эксперимент как способ образования семантического поля // Вестник Московского государственного областного университета. Серия «Лингвистика». - 2010. - № 5. - С. 7 10.

14. Иванова Н.А. Применение метода свободных ассоциаций в эмпирических социологических исследованиях // Вестник Санкт-Петербургского университета. Серия 12 «Социология». - 2013. - Вып. 3. - С. $116-122$.

15. Vergès P. L'evocation de l'argent: une méthode pour la définition du noyau central d'une représentation // Bulletin de psychologie. - 1992. - V. XLV. - № 405. - P. 203-209.

16. Левченко Е.В., Продовикова А.Г. Сравнение возможностей количественных и качественных методов в исследовании социальных представлений (на примере изучения представлений о сознании и бессознательном) // Вестник ВятГУ. - 2009. - № 4. - С. 79-92.

17. Жижина М.В. Особенности социальных представлений студенческой молодежи о масс-медиа // Психолого-педагогические исследования. - 2018. - Т. 10. - № 4. - С. 1-14. 
18. Конструирование образа будущего России в социальных медиа: Опросник на платформе Google Drive. URL: https://docs.google.com/forms/d/10pDs8TQnwYSgL3LVpj87mi1tglr-vfuen6th4bLqlE8/edit (дата обращения 12.10.2020).

19. Селезнева В.В., Евсикова Е.А., Тарвердян А.Ш. Английский разделительный вопрос как лингвоэкологичный феномен межличностного общения // Научный диалог. - 2019. - № 7. - С. 107-123.

20. Патрушева Л.С. Хештегирование как новый коммуникативный процесс // Вестник Удмуртского университета. Серия «История и филология». - 2018. - Т. 28. - № 3. - С. 471-475.

21. Черняева Г.В. Психологическое благополучие как атрибутивная составляющая профессионального развития личности // Психологическое благополучие современного человека: материалы Международной заочной научно-практической конференции 11 апреля 2018 г. - Екатеринбург: [б. и.], 2018. T. 1. - C. 338-344.

Поступила 27.11.2020 
UDC 316.774:159.923

\title{
HASHTAGS AS A REFLECTION OF VISIONS OF THE FUTURE REPRESENTATIONS BY «DIGITAL NATIVE»
}

\author{
Tatiana V. Konyukhova, \\ konykhova@tpu.ru \\ Elana V. Rodionova, \\ eva@tpu.ru \\ National Research Tomsk Polytechnic University, \\ 30, Lenin avenue, Tomsk, 634050, Russia
}

Tatyana V. Konyukhova, Cand. Sc., associate professor, National Research Tomsk Polytechnic University.

Elena V. Rodionova, Cand. Sc., associate professor, National Research Tomsk Polytechnic University.

The paper highlights the issue of visual representation of a vision of the future in the everyday life of social media users based on hashes included in the nuclear-peripheral structure of the «digital native generation» representations. It was assumed that emotional well-being is an attribute of a successful career in the future for young users of the Instagtam network and is reflected in visualization practices through the hashtags they use. The target audience of the study was 170 young people (118 females and 52 males, respectively) aged 1825, who, according to subjective assessment, are active users of social media. The data collection set was carried out in August-September 2020. The study used method of free verbal associations and prototypical anal$y$ sis according to $P$. Vergès. The ratio of future vision according to the social constructs analyzed in the given paper «Emotional well-being in the future» and "Career in the future» by subgroups "for oneself» and "for Russia" among the respondents allows authors to mark that the general tone of hashtags proposed by the research participants is predominantly positive. Common hashtags, one way or another overlapping in the core and areas of potential change, for the two constructs are \#happiness, \#well-being, \#success, \#confidence, \#freedom, \#calmness. A comparative analysis of the resulting array of hashtags allows us to write that in the practices of visualization on the Instagram network through published hashtags of young people, there is a certain relationship between emotional well-being, as an attributive component of career development, and a successful career in the future. This forms the basis for the development of new professional skills through selfconfidence, positive feelings, the degree of social activity.

Key words: Hashtag, future vision, digital native, emotional well-being, career.

The study was supported by the Russian Foundation for Basic Research and Expert Institute for Social Research, grant 20-011-31100.

\section{REFERENCES}

1. Petrova V.N. Metodika izucheniya obraza vozmozhnogo budushchego [Methodology for studying the image of a possible future]. Sibirskiy psikhologicheskiy zhurnal, 2002, no. 16-17, pp. 32-36.

2. Prenksy M. Digital natives, digital immigrants. On the Horizon, 2001, vol. 9 (5), pp. 1-6.

3. Prenksy M. Digital natives, digital immigrants, part II. Do they really think differently? On the Horizon, 2001, vol. 9 (6), pp. 1-6.

4. Thompson P. The digital natives as learners: technology use patterns and approaches to learning. Computers \& Education, 2013, vol. 65, pp. 12-33. DOI: https://doi.org/10.1016/j.compedu.2012.12.022. 
5. Bowe B.J., Wohn D.Y. Are there generational differences? Social media use and perceived shared reality. Proc. of the 2015 International Conference on Social Media \& Society (SMSociety '15). Toronto, Ontario, Canada, 2015. pp. 1-5. DOI: https://doi.org/10.1145/2789187.2789200.

6. Barak M. Are digital natives open to change? Examining flexible thinking and resistance to change. Computers \& Education, 2018, vol. 121, pp. 115-123. DOI: https://doi.org/10.1016/j.compedu.2018.01.016.

7. Teo T. Do digital natives differ by computer self-efficacy and experience? An empirical study. Interactive Learning Environments, 2016, vol. 24 (7), pp. 1725-1739. DOI: 10.1080/10494820.2015.1041408.

8. Arpenteva M.R. Tsifrovye kochevniki osvaivayut mir [Digital nomads are taking over the world]. Druzhba Narodov, 2018, no. 8, pp. 192-196.

9. Colasante T., Lin L., De France K., Hollenstein T. Any time and place? Digital emotional support for digital natives. American Psychologist. Advance online publication, $2020 . \quad$ DOI: https://doi.org/10.1037/amp0000708.

10. Soloveva L.M. Tsifrovaya identichnost kak novy vid identichnosti cheloveka informatsionnoy epokhi [Digital identity as a new kind of human identity in the information age]. Obshchestvo: filosofiya, istoriya, kultura, 2018, no. 12 , pp. 40-43.

11. Statistika sotsialnykh setey v Rossii 2020 [Statistics of social networks in Russia 2020]. Available at: https://livedune.ru/blog/statistika_socsetej_v_rossii// (accessed 12 December 2020).

12. Tugusheva A.R. Predstavleniya o sotsialnoy uspeshnosti i lichnostnoe samoopredelenie yunoshestva. Avtoreferat Dis. ... kand. nauk. [Ideas of social success and personal self-determination of youth. Cand. Diss. Abstract]. Samara, 2007. 24 p.

13. Ilina V.A. Assotsiativny eksperiment kak sposob obrazovaniya semanticheskogo polya [Associative experiment as a way of forming a semantic field]. Vestnik Moskovskogo gosudarstvennogo oblastnogo universiteta. Seriya «Lingvistika», 2010, no. 5, pp. 7-10.

14. Ivanova N.A. Primenenie metoda svobodnykh assotsiatsiy v empiricheskikh sotsiologicheskikh issledovaniyakh [Application of the method of free associations in empirical sociological research]. Vestnik SanktPeterburgskogo universiteta. Seriya 12 «Sociologiya», 2013, vol. 3, pp. 116-122.

15. Vergès P. L'evocation de l'argent: une méthode pour la définition du noyau central d'une representation. Bulletin de psychologie, 1992, vol. XLV, no. 405, pp. 203-209.

16. Levchenko E.V., Prodovikova A.G. Sravnenie vozmozhnostey kolichestvennykh i kachestvennykh metodov $\mathrm{v}$ issledovanii sotsialnykh predstavleniy (na primere izucheniya predstavleniy o soznanii i bessoznatelnom) [Comparison of the possibilities of quantitative and qualitative methods in the study of social representations (on the example of the study of ideas about consciousness and the unconscious)]. Vestnik VyatGU, 2009, no. 4, pp. 79-92.

17. Zhizhina M.V. Osobennosti sotsialnykh predstavleniy studencheskoy molodezhi o mass-media [Features of social representations of student youth about mass media]. Psikhologo-pedagogicheskie issledovaniya, 2018, vol. 10, no. 4, pp. 1-14.

18. Konstruirovanie obraza budushchego Rossii v sotsialnykh media: oprosnik na platforme Google Drive [Constructing the image of Russia's future in social media: Questionnaire on the Google Drive platform]. Available at: https://docs.google.com/forms/d/10pDs8TQnwYSgL3LVpj87mi1tglr-vfuen6th4bLqlE8/edit (accessed 12 October 2020).

19. Selezneva V.V., Evsikova E.A., Tarverdyan A.Sh. Angliyskiy razdelitelny vopros kak lingvoekologichny fenomen mezhlichnostnogo obshcheniya [English dividing question as a linguo-ecological phenomenon of interpersonal communication]. Nauchny dialog, 2019, no. 7, pp. 107-123.

20. Patrusheva L.S. Kheshtegirovanie kak novy kommunikativny protsess [Hashtagging as a new communicative process]. Vestnik Udmurtskogo universiteta. Seriya «Istoriya i filologiya», 2018, vol. 28, no. 3, pp. 471-475.

21. Chernyaeva G.V. Psikhologicheskoe blagopoluchie kak atributivnaya sostavlyayushchaya professionalnogo razvitiya lichnosti [Psychological well-being as an attributive component of the professional development of the individual]. Psikhologicheskoe blagopoluchie sovremennogo cheloveka. Materialy Mezhdunarodnoy zaochnoy nauchno-prakticheskoy konferentsii [Psychological well-being of a modern man. Proc. of International scientific-practical conference]. Ekaterinburg, 11 April 2018. Vol. 1. pp. 338-344.

Received: 27 November 2020. 